\title{
Taste disturbances following middle ear surgery
}

\author{
Gurung U, Bhattarai H, Shrivastav RP \\ Ganeshman Singh Memorial Academy of ENT-HN studies, Tribhuvan University Teaching Hospital, Kathmandu.
}

Correspondence to: Dr Urmila Gurung, Ganeshman Singh Memorial Academy of ENT-HN Studies, Tribhuvan University Teaching Hospital, Kathmandu, Nepal

Email:dr.urmila.gurung@gmail.com

\begin{abstract}
Introduction: Iatrogenic chorda tympani nerve (CTN) injury during middle ear surgery is quite common. The objective of ours study is to observe frequency \& types of CTN injury during middle ear surgery and assess types of post-operative taste disturbances and their functional recovery.

Methods: Patients who underwent middle ear surgery from $1^{\text {st }}$ October 2005 to $1^{\text {st }}$ January 2007 in Tribhuvan University Teaching Hospital were divided into 6 groups according to intraoperative CTN manipulation as; seen but not handled, handled but not stretched, stretched but intact, cut while stretching, cut while using burr and clean cut with scissors. Subjective assessment of taste disturbance was done after 2 days \& $2,4 \& 6$ months post-operatively and categorized as altered taste sensation/metallic taste, tongue numbness and dry mouth.

Results: Amongst 260 patients, CTN was seen but not handled in 52/260 (20\%), handled but not stretched in 54/260 (20.75\%), stretched but intact in 66/260 (25.38\%), cut while stretching in 17/260 (6.5\%), cut while using burr in 29/260 (11.15\%) and clean cut with scissors in 42/260 (16.15\%) patients. Eleven out of 260 patients ( $4.2 \%)$ symptomatic amongst which 6/11 (54.5\%) had altered taste sensation, $4 / 11(36.3 \%)$ had tongue numbness and $1 / 11(9 \%)$ had dry mouth. Complete recovery occurred in $9 /$ $11(81.8 \%)$ patients by 6 months.

Conclusion Though iatrogenic CTN injury was common during middle ear surgery, frequency of taste disturbance was comparatively less, commonest type of CTN injury being stretched but intact. The most common post-operative taste disturbance was altered taste sensation/metallic taste. Most patients recovered completely by 6 months. Functional recovery was earlier when CTN was preserved than when sectioned.
\end{abstract}

Keywords: CTN, middle ear surgery, taste disturbance

\section{Introduction}

Middle ear surgery is a common surgery in otorhinolaryngology practice. The various middle ear surgeries done in our setup are underlay myringoplasty, mastoidectomy, stapedectomy, tympanoplasty, tympanotomy, ossiculoplasty. These surgeries share the same surgical access to middle ear i.e. elevation of tympanomeatal flap. While elevating the flap, the CTN which lies immediately medial to the tympanic membrane, is seen running forward from posterior canaliculus in between the handle of malleus and incus. ${ }^{1}$
Iatrogenic CTN injury during middle ear surgery is a well recognized complication. ${ }^{2}$ The nerve may be manipulated in order to remove cholesteatoma, granulation tissue and for adequate visualization of surgical field as in procedures like ossiculoplasty, stapedectomy and tympanotomy. The injuries that CTN can sustain vary from simply being touched to stretched or sectioned.

Taste disturbance following CTN injury, though seldom reported, is a recognized possible sequelae. ${ }^{3}$ Despite trauma to CTN, studies have suggested that recovery of taste disturbance is possible. ${ }^{4}$ So, even if any patient develops taste disturbance post-operatively, there is chance of 
recovery of taste function later with time.

Pre-operative counseling related to complications following middle ear surgery is prioritized to otological and facial nerve complications whereas taste disturbance is hardly addressed. This study has been conducted to observe the frequency and types of CTN injury during middle ear surgery, to assess the types of taste disturbances postoperatively and their functional recovery. This study will help us to find whether iatrogenic CTN injury has a major impact on taste sensation and if so how long it will take to recover. Knowing the natural history of taste disturbance following CTN manipulation in middle ear surgery will help us in an informed surgical decision making and as a consequence reduce post-operative taste disturbances. There has not been any study of similar kind in our institute yet so far, so this study will give an impression of the scenario here in our setup.

\section{Methods}

It was a prospective, analytical and longitudinal study conducted in the Department of Otorhinolaryngology and Head and Neck Surgery, Tribhuvan University Teaching Hospital, Kathmandu, Nepal from $1^{\text {st }}$ October 2005 to $1^{\text {st }}$ January 2007. The total population taken to calculate the sample size was 426 which was the number of middle ear surgeries done in patients above 12 years of age in the previous 15 months at Tribhuvan University Teaching Hospital. Taking 95\% confidence level with $4 \%$ absolute precision and $50 \%$ expected proportion to population, the sample size calculated was 250 .

Patients of age more than 12 years, of both sex and those who were undergoing middle ear surgery namely underlay myringoplasty, mastoidectomy (including excision of postero-superior retraction pocket, atticotomy), stapedectomy, tympanoplasty and tympanotomy were included in the study. Patients who were excluded were those with previous middle ear surgery, with medical conditions that could be associated with altered taste sensation like those with diabetes, with mental retardation and with neurological deficits, previous surgery on the tongue, salivary gland or any other surgery that were likely to alter the taste and patients who did not come for $2^{\text {nd }}$ follow up.

The middle ear surgeries were categorized into 5 groups i.e. underlay myringoplasty, mastoidectomy, stapedectomy, tympanoplasty and tympanotomy. During middle ear surgery, the type of CTN injury was noted as

\author{
- Seen but not handled /not seen \\ - Handled but not stretched \\ - Stretched but intact \\ - Cut
o while stretching
o while using burr
o clean cut with scissors

If CTN was not seen, no attempt was made to search for it. The first assessment of taste was carried out on the $1^{\text {st }}$ day of dressing i.e. within 48-72 hours post-operatively. However, patients were not specifically asked for the taste symptoms. If any taste disturbance was noticed by the patients, it was recorded as

- Altered taste sensation/metallic taste

- Tongue numbness

- Dry mouth

It was noted whether the patient was aware of the symptom or not. Post-operatively, all the patients were again assessed after 2 months in the out-patient department. Only those who were symptomatic at $2^{\text {nd }}$ post-operative month follow up were then further assessed at $4^{\text {th }} \& 6^{\text {th }}$ post-operative months. The $4^{\text {th }} \& 6^{\text {th }}$ post-operative month follow ups were done via telephone.

The result of our study was analyzed in terms of frequency and types of CTN injury, occurrence of types of taste disturbances and the extent of recovery of symptoms in relation to the intraoperative injury to the CTN and also the type of middle ear surgery. Fisher exact test was used for analysis and $p$ value less than 0.05 was taken as statistically significant value.

\section{Results}

There were a total of 324 middle ear surgeries done from $1^{\text {st }}$ October 2005 to $1^{\text {st }}$ January 2007. Out of the 324 patients, 260 patients were included while 64 patients were excluded of which 22 failed to come for $2^{\text {nd }}$ follow up, 38 had previous middle ear operation, 3 were diabetic and 1 was mentally retarded. Amongst 260 patients who were included, 126 were males and 134 were females. The age ranged from 14 to 60 years.

Out of the 260 patients, the number of patients who underwent underlay myringoplasty was 153 (58.8\%) (73 males, 80 females), mastoidectomy was $81(31.15 \%$ ) (36 males, 45 females), stapedectomy was $14(5.3 \%)$ (9 males, 5 
females), tympanoplasty was 7 (2.6\%) (5 males, 2 females) and tympanotomy was 5 (1.9\%) (3 males, 2 females).

In total 260 middle ear surgeries, the distribution of each type of CTN injury was noted as follows; seen but not handled/not seen in 52/260 (20\%), handled but not stretched in 54/260 (20.75\%), stretched but intact in 66/260 (25.38\%), cut while stretching in $17 / 260(6.5 \%)$, cut while using burr in $29 / 260(11.15 \%)$ and clean cut with scissors in $42 / 260$ $(16.15 \%)$ patients. So, in total $80 \%$ patients the chorda sustained some form of injury while in $20 \%$ patients the chorda was seen but not handled/not seen where chorda most likely sustained no injury.

There were 11 out of 260 patients $(4.2 \%)$ who had taste disturbances post- operatively. Four $(36.3 \%)$ were male while $7(63.7 \%)$ were female. The age ranged from 19 to 60 years (mean age 31.3 years). Out of 11 patients, 5 patients $(45.4 \%)$ were aware of the symptoms. Seven out of 11 (63.6\%) noticed symptoms in the first assessment i.e. within 48-72 hours of post-operative period while $4 / 11(36.3 \%)$ noticed it between the first assessment and second follow up i.e. at $2^{\text {nd }}$ month of post-operative period.

Symptom wise, 6/11 (54.5\%) patients had altered taste sensation/metallic taste sensation, 4/11 (36.3\%) patients had tongue numbness and 1/11 (9\%) patient had dry mouth (Fig. 1).

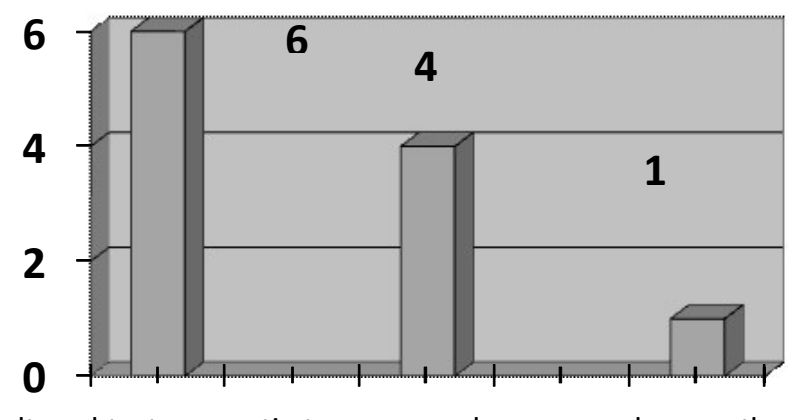

altered taste sensatiortongue numbness

dry mouth

Fig. 1: Types of taste disturbances

Amongst the different types of middle ear surgeries, the frequency of taste disturbances was 6/153 (3.9\%) in underlay myringoplasty group, 3/81(3.7\%) in mastoidectomy group, $1 / 14(7.1 \%)$ in stapedectomy group, $0 / 7(0 \%)$ in tympanoplasty group and $1 / 5(20 \%)$ in tympanotomy group. So tympanotomy group had the highest rate of post-operative taste disturbance, followed by stapedectomy, myringoplasty and mastoidectomy group. None of the patients in tympanoplasty group developed taste disturbance. (Table 1).
Table 1: Distribution of symptomatic cases according to the types of middle ear surgery.

$\begin{array}{lll}\begin{array}{l}\text { Type of middle } \\ \text { ear surgery }\end{array} & \begin{array}{l}\text { Number of } \\ \text { symptomatic } \\ \text { patients }\end{array} & \begin{array}{l}\text { Percentage of } \\ \text { symptomatic } \\ \text { patients }\end{array} \\ \begin{array}{l}\text { Underlay } \\ \text { myringoplasty }(\mathrm{n}=153)\end{array} & 6 & 3.9 \% \\ \text { Mastoidectomy }(\mathrm{n}=81) & 3 & 3.7 \% \\ \text { Stapedectomy }(\mathrm{n}=14) & 1 & 7.1 \% \\ \text { Tympanoplasty }(\mathrm{n}=7) & 0 & 0 \% \\ \text { Tympanotomy }(\mathrm{n}=5) & 1 & 20 \%\end{array}$

Occurrences of taste disturbances seen in relation to the type of CTN injury were noted as follows; $1 / 52(1.9 \%)$ patient of seen but not handled/not seen group, 3/54 (5.5\%) patients of handled but not stretched group, 4/66 (6\%) patients of stretched but intact group and 3/42 $(7.1 \%)$ patients of clean cut with scissors group were symptomatic. None of the patients whose chorda were cut while stretching or cut while using burr were symptomatic. So, symptomatic patients were mostly found in the chorda clean cut with scissors group (Table 2).

Table 2: Distribution of symptomatic cases according to the types of chorda tympani nerve injury.

\begin{tabular}{llc}
$\begin{array}{l}\text { Type of chorda } \\
\text { tympani nerve } \\
\text { injury }\end{array}$ & $\begin{array}{l}\text { Number of } \\
\text { symptomatic } \\
\text { patients }\end{array}$ & Percentage \\
$\begin{array}{l}\text { Seen but not handled/ } \\
\text { not seen }(\mathrm{n}=52)\end{array}$ & 1 & $1.9 \%$ \\
$\begin{array}{l}\text { Handled but not } \\
\text { stretched }(\mathrm{n}=54)\end{array}$ & 3 & $5.5 \%$ \\
$\begin{array}{l}\text { Stretched but } \\
\text { intact(n=66) }\end{array}$ & 4 & $6 \%$ \\
$\begin{array}{l}\text { Cut while } \\
\text { stretching ( }=17)\end{array}$ & 0 & $0 \%$ \\
$\begin{array}{l}\text { Cut while using } \\
\text { burr (n=29) } \\
\text { Clean cut with } \\
\text { scissors (n=42) }\end{array}$ & 0 & $0 \%$ \\
\hline
\end{tabular}

Out of the 11 symptomatic patients, $9(81.8 \%)$ patients had complete recovery and $1(9 \%)$ patient had partial recovery while $1(9 \%)$ patient remained symptomatic in the $4^{\text {th }}$ follow up (6th month post-operative period). The reduction in number of symptomatic patients from 11 to 2 by $4^{\text {th }}$ follow up was statistically significant (p value 0.025 ).

Regarding recovery seen according to the type of CTN injury, in the seen but not handled/not seen group, there 
was 1 symptomatic patient who recovered by $2^{\text {nd }}$ follow up. So $1 / 1(100 \%)$ patients recovered (Table 3$)$.

In the handled but not stretched group, 3 symptomatic patients recovered by $2^{\text {nd }}$ follow up. So $3 / 3$ (100\%) patients recovered.

In the stretched but intact group, 2 were symptomatic at $1^{\text {st }}$ assessment. Two more patients became symptomatic by $2^{\text {nd }}$ follow up in addition to the 2 previous symptomatic patients so the total symptomatic patient at $2^{\text {nd }}$ follow up was 4 . By $3^{\text {rd }}$ follow up, 2 out of 4 symptomatic at $2^{\text {nd }}$ follow up became symptom free while 2 remained symptomatic. Both these patients recovered from the symptoms by $4^{\text {th }}$ follow up. So, by $4^{\text {th }}$ follow up, $4 / 4(100 \%)$ patients recovered.

In those patients whose chorda was clean cut with scissors, 1 patient was symptomatic at $1^{\text {st }}$ assessment. By $2^{\text {nd }}$ follow up, 2 more became symptomatic so the total symptomatic patients was 3 . These 3 remained symptomatic at $3^{\text {rd }}$ follow up also. By $4^{\text {th }}$ follow up, $1 / 3$ (33.3\%) was still symptomatic, $1 / 3(33.3 \%)$ had partial recovery while $1 / 3(33.3 \%)$ had complete recovery. of tongue. The greater superficial petrosal nerve, branch of facial nerve, mediates taste from the palate. Lingual branches of the glossopharyngeal nerve carry taste from the posterior $1 / 3$ of the tongue. The fibres from the pharyngeal plexus of vagus nerve form special visceral afferents of base of tongue and epiglottis. ${ }^{5}$ The sensory nerve fibres from these nerves except the greater superficial petrosal nerve unite in the nucleus of tractus solitarius in medulla oblongata. There, they synapse on $2^{\text {nd }}$ order neurons, the axons of which relay fibres to the thalamus. Impulses are relayed from there to taste projection area in cerebral cortex. ${ }^{6}$ Because of this complex neural network, injury to any one of these nerves is unlikely to produce significant permanent disturbance in taste sensation.

Though CTN injury is common in middle ear surgery, according to different literature those who develop taste disturbance ranges from $14-28 \% .^{2,3,4,7,8}$ In our study also, although CTN injury occurred in $80 \%$, only $4.2 \%(11 / 260)$ patients developed post-operative taste disturbance. Return of normal taste function after injury could be due to a number of reasons. The inhibition of glossopharyngeal nerve

Table 3: Time frame of resolution of symptoms according to the type of chorda tympani nerve injury.

\begin{tabular}{|c|c|c|c|c|c|c|}
\hline $\begin{array}{l}\text { Types of chorda } \\
\text { tympani nerve injury }\end{array}$ & $\begin{array}{l}\text { Symptomatic } \\
1^{\text {st }} \text { assessment } \\
\text { (within } 48-72 \text { hours } \\
\text { of post-operative } \\
\text { period) }\end{array}$ & $\begin{array}{l}2^{\text {nd }} \mathrm{F} / \mathrm{U} \\
\left(2^{\text {nd }} \text { month of }\right. \\
\text { post-operative } \\
\text { period })\end{array}$ & $\begin{array}{l}3^{\text {rd }} \mathrm{F} / \mathrm{U} \\
4^{\text {th }} \text { month of } \\
\text { post-operative } \\
\text { period) }\end{array}$ & $\begin{array}{l}4^{\text {th }} \mathrm{F} / \mathrm{U} \\
\left(6^{\text {th }} \text { month of }\right. \\
\text { post-operative } \\
\text { period })\end{array}$ & $\begin{array}{l}\text { Complete } \\
\text { recovery at } \\
4^{\text {th }} \mathrm{F} / \mathrm{U}\left(6^{\text {th }}\right. \\
\text { month of post- } \\
\text { operative } \\
\text { period) }\end{array}$ & $\begin{array}{l}\text { Percentage } \\
\text { of complete } \\
\text { recovery }\end{array}$ \\
\hline $\begin{array}{l}\text { Seen but not handled/ } \\
\text { not seen }(\mathrm{n}=1) \\
\text { Handled but not }\end{array}$ & 1 & - & - & - & 1 & $100 \%$ \\
\hline $\begin{array}{l}\text { stretched }(n=3) \\
\text { Stretched but }\end{array}$ & 3 & - & - & - & 3 & $100 \%$ \\
\hline $\begin{array}{l}\text { intact }(\mathrm{n}=4) \\
\text { Cut while using }\end{array}$ & 2 & 4 & 2 & - & 4 & $100 \%$ \\
\hline $\begin{array}{l}\text { stretching }(\mathrm{n}=0) \\
\text { Cut while using }\end{array}$ & - & - & - & - & - & - \\
\hline $\begin{array}{l}\text { burr }(n=0) \\
\text { Clean cut with }\end{array}$ & - & - & - & - & - & - \\
\hline scissors $(\mathrm{n}=3)$ & 1 & 3 & 3 & 2 & 1 & $33.3 \%$ \\
\hline
\end{tabular}

\section{Discussion}

Taste disturbance following middle ear surgery is an overshadowed consequence. It occurs occasionally and is noticed by a few patients only. It is less frequently brought to the notice of the operating otologist by the patient.

The sense of taste depends on the interaction between several nerves. The CTN carries taste from the anterior $2 / 3$ function by CTN in the tractus solitarius may be released after the latter is injured. This release of inhibition serves as compensation mechanism that preserves normal taste .4, 9 When there is localized taste loss in areas innervated by CTN, there are also intensified sensations from other areas innervated by glossopharyngeal nerve. ${ }^{2}$ Alternatively, there may be cross innervation from contralateral CTN. So, unilateral CTN injury has little effect on the whole mouth taste sensation. 
Taste disturbances can be metallic taste, bitter, salty or sore sensation, tongue numbness or dry mouth. ${ }^{4}$ Dry mouth is due to the injury to secretomotor fibres to the salivary gland, which are more sensitive to trauma than the special visceral afferent fibres to the tongue. ${ }^{10}$ Metallic taste or altered taste sensation was frequently noticed by symptomatic patients in this study.

Any form of injury to CTN can cause taste disturbances, the degree of taste disturbance probably depends on the severity of injury. Conflicting results are found in relation to whether preserving or sectioning of CTN causes more patients to be symptomatic. Various studies found patients to be symptomatic when the CTN was sectioned as compared to when it was preserved during stapedectomy ${ }^{8}$ middle ear surgeries done for chronic otitis media with or without cholesteatoma, tympanosclerosis, otosclerosis and middle ear anomaly. ${ }^{3,11}$. On the contrary, other studies concluded that stretching and preserving the nerve caused symptoms rather than sectioning the nerve. ${ }^{4,7,12}$ Our study found the association of taste disturbance more when CTN was clean cut with scissors as compared to other types of injuries. Interestingly, one patient was symptomatic even when the CTN was not seen. This could be because CTN could have been unknowingly touched or tugged while raising the annulus as it could have adhered to thickened tympanic membrane due to chronic otitis media. ${ }^{3}$

Patients with non-inflammatory diseases like otosclerosis and ossicular disruption tend to have post-operative taste related symptoms more than in patients with inflammatory diseases like chronic otitis media. ${ }^{7,13,16}$ In our study also, the frequency of taste disturbance was more in tympanotomy group and stapedectomy group patients as compared to patients in mastoidectomy group and patients in underlay myringoplasty group. The low rate of symptoms in mastoidectomy group may be due to the chronic nature of cholesteatomatous disease that may damage the CTN and cause gradual decrease in taste sensation. Thus when the CTN is subsequently traumatized at operation, the relative decrease in taste function is less and so perhaps reported less frequently. On the other hand, in tympanotomy group, the CTN previously unaffected by disease is likely to be functioning normally. So, the relative decrease in taste function is more prominent in this group. ${ }^{7,12,14}$

Recovery following CTN injury is an ongoing process. In our study $9 / 11(81.8 \%)$ symptomatic patients recovered completely by 6 months post-operatively. Change in patient's symptoms has shown to occur in 6 months to more than 2 years after middle ear surgery. ${ }^{3,11}$ So Saito et $\mathrm{al}^{3}$ suggested that longer follow up was necessary to fully assess the functional recovery of taste function. The recovery of taste function after sectioning of nerve is unclear whether it is because of compensation or regeneration.

Various factors play role in recovery following CTN injury, one factor being the type of injury sustained. Studies have shown that preserving CTN showed recovery as early as 3 to 4 months as compared to 6 to 7 months when it was sectioned. ${ }^{3,8}$ Tomomi et al emphasized on preserving the CTN especially in patients engaged in cooking. ${ }^{15}$ Functional recovery of taste disturbance in our study was early in those where CTN was preserved and once CTN was sectioned, it took longer time to recover. ${ }^{15}$

Age plays an important role in the recovery of taste function after middle ear surgery. ${ }^{17}$ Sone et $a l^{12}$ found that the rate of complete recovery was $83 \%$ in 0 -20 years group, $53 \%$ in 21 40 years group and 44\% in 41-60 years group. Younger patients had significantly higher rate of recovery of CTN function. Literature shows ageing deteriorates taste function irrespective of disease or iatrogenic cause. ${ }^{18}$ There was one patient who had no recovery of taste function even after 6 months of surgery. She was a 60 years old lady whose CTN was clean cut during underlay myringoplasty. Presence of symptom in this particular patient could have been because of her age and because the CTN was sectioned. Recovery of her taste function could have been better assessed if we had followed her up for a longer period of time.

\section{Conclusions}

As compared to high frequency of injury to CTN during middle ear surgery, the frequency of taste disturbance was less, the commonest type of CTN injury being stretched but intact.The most common post-operative taste disturbance found was the symptom of altered taste sensation/metallic taste. Functional recovery was earlier when the chorda was preserved as compared to when the CTN was sectioned. So, it is our recommendation that where ever possible, CTN should be preserved. Since our study assessed a small number of symptomatic patients, further studies are required to assess the occurrence and recovery of taste disturbances following middle ear surgery.

\section{References}

1. Shenoi MP. Surgical approaches to middle ear and mastoid.In:Ballantyne JC, Morrison A.(eds.) Rob \& Smith's Operative Surgery Ear. $4^{\text {rth }}$ ed.London: Butterworths;1986.p.47-66.

2. Clark PAM, O'Malley S. Chorda tympani nerve function after middle ear surgery. Otology \& Neurotology 2007 April; 28(3):335-340. 
3. Saito T, Manabe Y, Shibamori Y, Yamagishi T, Igawa H, Tokuriki $\mathrm{M}$ et al. Long term follow-up results of electrogustometry and subjective taste disorder after middle ear surgery. Laryngoscope 2001; 111:2064-70.

4. Gopalan P, Kumar M, Gupta D, Phillipps J J. A study of chorda tympani nerve injury and related symptoms following middle ear surgery. J Laryngol Otol 2005;119:189-192.

5. Pattern PJ. Clinical neuroanatomy. In:Gleeson M.Scott Brown's Otolaryngology. $6^{\text {th }}$ ed. London:Butterworth -Heinemann ;1997.p.1/16/1-28.

6. Ganong WF. Smell and taste. Review of medical physiology $20^{\text {th }}$ ed. Boston:McGraw-Hill;2002.p.180186.

7. Micheal P, Raut V. Chorda tympani nerve injury; operative findings and postoperative symptoms. Otolaryngol Head and Neck surgery 2007; 136(6):978981.

8. Mahendran S, Hogg R, Robinson MJ. To divide or manipulate the chorda tympani in stapedotomy. European Arch Otolaryngol 2005 June; 262(6): 482-7.

9. Kveton JF, Bartoshuk LM. The effect of unilateral chorda tympani damage on taste. Laryngoscope 1994; 104:25-9.

10. Chilla R, Nicklatsch J, Arglebe C. Late sequelae of iatrogenic damage to chorda tympani nerve. Acta Otolaryngol 1982; 94:461-5.

11. Moon Jr CN, Pullen EW. Effects of chorda section during middle ear surgery. Laryngoscope 1963; 73:392405 .

12. Sone M, Sakagami M, Tsuji K, Mishiro Y. Younger patients have higher rate of recovery of taste function after middle ear surgery. Arch Otolaryngol Head Neck Surg Aug 2001; 127:967-969.

13. Sakagami M, Sone M, Tsuji K, Fukazawa K, Mishiro Y. Rate of recovery of taste function after preservation of chorda tympani nerve in middle ear surgery with special reference to type of disease. Ann Otol Rhinol Laryngol 2003; 112:52-7.

14. Gedikli O, Dogru H, Aydin G, Tuz M, Uygur, K Sari. Histopathological changes of chorda tympani in chronic otitis media. Laryngoscope 2001; 111: 724-7.
15. Tomomi N, Masafumi S, Meiko S, Toshihiko M, Yasuo M, Keijiro F. Taste function after section of chorda tympani nerve in middle ear. Auris nasus Larynx 2006; 33:13-17.

16. Tomita $\mathrm{H}$, Ikeda $\mathrm{M}$.Clinical use of electrogustometry:strengths and limitations. Acta Otolaryngol 2002;546:27-38.

17. Sakagami M. Taste disturbance and its recovery after middle ear surgery. Chem Senses 2005;30(suppl 1):12201221.

18. Terada T, Sone M, Tsuji K, Mishiro Y, Sakagami M. Taste function in elderly patients with unilateral middle ear diseases. Acta Otolaryngol 2004; 124(Suppl 553):113-116. 